\title{
BASIC RESEARCH
}

\section{Adrenomedulline improves ischemic left colonic anastomotic healing in an experimental rodent model}

\author{
Oguzhan Karatepe,' Idris Kurtulus,' Orhan Yalcin,' Muharrem Battal,' Gulcin Kamali," Timucin Aydin' \\ 'Okmeydani Education and Research Hospital, Department of Surgery, Okmeydani, Istanbul/Turkey. "Okmeydani Education and Research Hospital, \\ Department of Pathology, Okmeydani, Istanbul/Turkey.
}

BACKGROUND: Leakage from colonic anastomosis is a major complication causing increased mortality and morbidity. Ischemia is a well-known cause of this event. This study was designed to investigate the effects of adrenomedullin on the healing of ischemic colon anastomosis in a rat model.

METHODS : Standardized left colon resection $3 \mathrm{~cm}$ above the peritoneal reflection and colonic anastomosis were performed in $\mathbf{4 0}$ Wistar rats that were divided into four groups. To mimic ischemia, the mesocolon was ligated $2 \mathrm{~cm}$ from either side of the anastomosis in all of the groups. The control groups (1 and 2) received no further treatment. The experimental groups ( 3 and 4 ) received adrenomedullin treatment. Adrenomedullin therapy was started in the perioperative period in group 3 and 4 rats (the therapeutic groups). Group 1 and group 3 rats were sacrificed on postoperative day 3. Group 2 and group 4 rats were sacrificed on postoperative day 7. After careful relaparotomy, bursting pressure, hydroxyproline, malondialdehyde, interleukin 6, nitric oxide, vascular endothelial growth factor, and tumor necrosis factor alpha levels were measured. Histopathological characteristics of the anastomosis were analyzed.

RESULTS : The group 3 animals had a significantly higher bursting pressure than group 1 ( $p<0.05$ ). Hydroxyproline levels in group 1 were significantly lower than in group $3(p<0.05)$. The mean bursting pressure was significantly different between group 2 and group $4(p<0.05)$. Hydroxyproline levels in groups 3 and 4 were significantly increased by adrenomedullin therapy relative to the control groups $(p<0.05)$. When all groups were compared, malondialdehyde and nitric oxide were significantly lower in the control groups $(p<0.05)$. When vascular endothelial growth factor levels were compared, no statistically significant difference between groups was observed. Interleukin 6 and tumor necrosis factor alpha were significantly decreased by adrenomedullin therapy $(p<0.05)$. The healing parameters and inflammatory changes (e.g., granulocytic cell infiltration, necrosis, and exudate) were significantly different among all groups $(p<0.05)$.

CONCLUSION : Adrenomedullin had positive effects on histopathologic anastomotic healing in this experimental model of ischemic colon anastomosis.

KEYWORDS: Colonic anastomosis; Ischemia; Adrenomedullin; Oxidative damage; Neovascularization.

Karatepe O, Kurtulus I, Yalcin O, Battal M, Kamali G, Aydin T. Adrenomedulline improves ischemic left colonic anastomotic healing in an experimental rodent model. Clinics. 2011;66(10):1805-1810.

Received for publication on May 23, 2011; First review completed on June 22, 2011; Accepted for publication on July 4, 2011

E-mail: drkaratepe@yahoo.com

Tel.: 905335408070

\section{INTRODUCTION}

Colon resections and anastomosis are frequent surgical procedures performed in general surgery. Although these are reliable operations, leakage of anastomoses can lead to serious complications, which may cause death. ${ }^{1-3}$ Colonic mucosal blood flow, the anastomosis technique, inflammation, the age of the patient, the nutritional state of the patient, additional diseases, medications, and the type of operation can affect the

Copyright @ 2011 CLINICS - This is an Open Access article distributed unde the terms of the Creative Commons Attribution Non-Commercial License (http:// creativecommons.org/licenses/by-nc/3.0/) which permits unrestricted noncommercial use, distribution, and reproduction in any medium, provided the original work is properly cited.

No potential conflict of interest was reported. leakage of colonic anastomoses. ${ }^{4}$ In particular, insufficient colonic mucosal blood flow, the quantity of bacteria colonization, chemotherapy agents, radiation, and corticosteroid use may cause complications in colon anastomosis. ${ }^{5}$ Although the most important factors for success in anastomotic surgery are surgical experience and technique, some additional drugs and tools are also necessary in certain circumstances. Colonic anastomoses performed in an ischemic and contaminated abdomen can be particularly problematic, and the risk of anastomotic leakage increases under such circumstances. ${ }^{6}$ Various drugs and methods have been tried to reduce anastomotic leakage, but no agents are currently known to prevent ischemic colonic anastomotic leakage effectively.

Adrenomedullin (ADM), which was initially obtained from pheochromocytoma during an investigation into the effects of certain peptides on the levels of thrombocyte 
cAMP, is a peptide consisting of 52 amino acids. ${ }^{7-9}$ ADM levels differ according to disease state. It has strong hypotensive and vasodilator effects in vivo following intravenous administration. It promotes non-adrenergic and non-cholinergic vasodilator responses in systematic and pulmonary blood vessels via endothelium-dependent and endothelium-independent mechanisms. Thus, blood flow to the heart, kidneys, brain, and lungs increase when ADM levels rise. $^{10}$ ADM mRNA was discovered in duodenal, small intestinal, cecal, and colonic mucosae by Kita et al. ${ }^{11}$ in 1993. They considered ADM to be part of gastrointestinal endocrine system. Hinson et al. ${ }^{12}$ offered a more precise definition of the endocrine cells present in the gastrointestinal system and proposed that these cells comprised the subgroup of enterochromaffin cells of the gastrointestinal system. Isumi et al. reported that ADM was also secreted from endothelial and smooth muscle cells and played a role in the induction of numerous molecules, such as TNF- $\alpha$ and IL-1. ${ }^{13,14}$

Despite the numerous well-known effects of ADM, its effects on the gastrointestinal system are not entirely understood. The aim of this study is to investigate the effect of ADM, a strong vasoactive agent, on ischemic colon anastomoses and oxidative damage in colonic mucosa.

\section{METHODS}

This study was performed between October 2008 and January 2009 in the laboratory of Istanbul University, Institute of Experimental Medical Research after approvals were obtained from the animal ethics committee.

\section{Animals}

A total of 40 female Wistar albino rats were used in the study. Their mean weight was $220 \mathrm{~g}$. Rats were placed in individual cages with alternate light and dark cycles of 12 hours. Experimental animals were pre- and postoperatively fed a normal diet. Rats were randomly divided into two main groups: a control group, which received ischemic colonic anastomosis only, and an experimental group, which received both ischemic colonic anastomosis and ADM.

The control group $(\mathrm{n}=16)$ was divided into two subgroups: group $1(\mathrm{n}=8$, sacrificed on postoperative day 3 ) and group $2(n=8$, sacrificed on postoperative day 7$)$. The experimental group $(n=16)$ was also divided into two subgroups: group 3 ( $n=8$, sacrificed on postoperative day 3 ) and group $4(n=8$, sacrificed on postoperative day 7$)$.

\section{Surgical Procedure}

Following intraperitoneal injection of ketamine $10 \mathrm{mg} /$ $\mathrm{kg}$, the incision sight for a median laparotomy was shaved and cleaned. The incision line was painted with batticon solution, and a median laparotomy was performed. The distal portion of the left colon was located, and a 1-cm-long colonic segment was removed. Blood vessels supplying this site were ligated $2 \mathrm{~cm}$ proximal and $2 \mathrm{~cm}$ distal to the anastomotic site after the fecal content was removed. Then an end-to-end anastomosis was performed with a singlelayer 6/0 polypropylene suture, and the abdomen was closed. The animals were permitted to eat 24 hours after the surgery.

Rats in groups 1 and 3 were sacrificed on day 3, and rats in groups 2 and 4 were sacrificed on day 7 by administration of a ketamine overdose via cardiac puncture. Then the animals were assessed. Sampling for histopathological and biochemical examinations was performed following the measurement of the anastomotic bursting pressure in all of the rats.

\section{Treatment with Adrenomedullin}

Two micrograms per day of rat ADM were administered subcutaneously to the group 3 and 4 rats beginning during the early postoperative period and continuing for three days (Adrenomedullin 1-50, Rat 100 micrograms, Calbiochem, U.S. and Canada).

\section{Measurement of Bursting Pressure}

A second laparotomy was performed through a median incision on the group 1 and group 3 rats on postoperative day 3 and on the group 2 and group 4 rats on postoperative day 7. After the animals were euthanized, the anastomosis site was identified by the presence of polypropylene sutures. The segment containing the anastomotic site was separated without dissecting the adhesions too much, and a $2 \mathrm{~cm}$ proximal and $2 \mathrm{~cm}$ distal side segment was prepared. Later, the proximal bowel segment was cannulated and connected to an insufflation pump, and the distal part was also ligated. Insufflation was initiated in a container filled with physiological serum. The anastomotic bursting pressure was recorded for all of the study animals by noting the pressure at the moment the first bubble was observed.

\section{Measurement of Hydroxyproline}

Hydroxyproline was measured after storing the perianastomotic bowel segment at $-70^{\circ} \mathrm{C}$. Hydroxyproline was evaluated spectrophotometrically at $560 \mathrm{~nm}$ using the Prockop and Kivirikko technique. ${ }^{15}$

\section{Assessment of Oxidative Damage}

Tissue samples were homogenized in $1 / 5(\mathrm{w} / \mathrm{v})$ phosphate-buffered saline solution after being cut into small pieces. Then, the values were measured using a Shimada $1601 \mathrm{UV} / \mathrm{V}$ is spectrophotometer (Shimada, Japan) according to the method of Lowry and Rosebrough. Protein concentration was determined according to the Lowry method. $^{16}$

\section{Measurement of Malondialdehyde (MDA)}

MDA was measured using the tributyric acid method. Iron sulfate $(1 \mu \mathrm{mol} / \mathrm{L})$ was added at $\mathrm{pH}$ 2.0. Absorption was measured at $535 \mathrm{~nm}$. The normal range of MDA concentrations in tissue was determined to be $<1.0 \mu \mathrm{mol} /$ $\mathrm{L} / \mathrm{mg}$ tissue.

\section{Measurement of Nitric Oxide (NO)}

A colorimetric method was used to measure $\mathrm{NO}$ (Boehringer Mannheim kit, cat no: 175 6281). Typical values of NO concentration in tissue were $<0.5 \mathrm{pg} / \mathrm{ml} / \mathrm{mg}$ tissue.

\section{Measurement of Vascular Endothelial Growth Factor (VEGF)}

Plaques covered with DiaClone anti-polyclonal animal vascular endothelial growth factor were used. These tests were performed using an automatic Best 2000 (Biokit Elisa System, USA) microelisa. Normal values for VEGF concentration in tissue were $<50 \mathrm{pg} / \mathrm{ml} / \mathrm{mg}$ tissue. 
Table 1 - Biochemical assessment and bursting pressures in groups 1 and 3, sacrificed on postoperative day 3.

\begin{tabular}{|c|c|c|c|c|c|}
\hline \multirow[t]{2}{*}{ Parameters } & \multicolumn{2}{|c|}{ Group 1} & \multicolumn{3}{|c|}{ Group 3} \\
\hline & Mean & $S D$ & Mean & $S D$ & $p$-value \\
\hline IL-6 (pg/ml/mg tissue) & 3.18 & \pm 0.60 & 2.67 & \pm 0.32 & 0.032 \\
\hline$T N F-\alpha(\mathrm{ng} / \mathrm{ml} / \mathrm{mg}$ tissue $)$ & 3.77 & \pm 0.25 & 3.35 & \pm 0.37 & 0.032 \\
\hline MDA ( $\mu \mathrm{g} / \mathrm{ml} / \mathrm{mg}$ tissue) & 1.67 & \pm 0.25 & 1.10 & \pm 0.21 & 0.005 \\
\hline NO (pg/ml/mg tissue) & 0.68 & \pm 0.17 & 0.37 & \pm 0.09 & 0.003 \\
\hline $\operatorname{VEGF}(\mathrm{pg} / \mathrm{ml} / \mathrm{mg}$ tissue) & 40.75 & \pm 8.10 & 42.75 & \pm 6.90 & 0.607 \\
\hline Hydroxyproline ( $\mu \mathrm{g} /$ tissue) & 228 & \pm 16.46 & 253.75 & \pm 15.11 & 0.007 \\
\hline Bursting pressure $(\mathrm{mmHg})$ & 130.25 & \pm 2.96 & 136.50 & \pm 1.92 & $<0.001$ \\
\hline
\end{tabular}

\section{Measurement of TNF (Tumor Necrosis Factor) Alpha and IL-6 (Interleukin-6)}

TNF- $\alpha$ and IL-6 levels in tissue homogenate were measured by enzyme-linked immunosorbent assay (ELISA), (Quantikine Sensitivity Human, R\&D Systems, USA). Typical values for IL- 6 and TNF- $\alpha$ concentration in tissue were $<3.0 \mathrm{pg} / \mathrm{ml} / \mathrm{mg}$ and $<3.5 \mathrm{ng} / \mathrm{ml} / \mathrm{mg}$, respectively.

\section{Histopathological Evaluations}

Tissues were fixed in $10 \%$ formaldehyde for histopathological examination, stained with hematoxylin-eosin, and evaluated under $x 40, x 100, x 200$, and $x 400$ magnification. Recovery parameters and inflammatory changes were evaluated semiquantitatively. These included granulocyte cell infiltration, fibroblast cell infiltration, necrosis, exudate and new capillary formation. The results of each evaluation were scored between 0 and 3 .

\section{Statistical Evaluation}

Quantitative results were expressed as the mean \pm standard deviation. The Mann-Whitney $U$ test was used to make comparisons between groups. Multiple comparisons and multiple assessments between groups were performed using Tukey's post-hoc HSD test. $P$-values of $<0.05$ were considered statistically significant. Statistical Package for Social Sciences (SPSS) for Windows 15.0 (SPSS Inc., Chicago, IL, USA) was used for statistical calculations.

\section{RESULTS}

Rats were sacrificed on day 3 or 7 . Anastomotic leakage was detected in one rat in each group. These rats were excluded from evaluation. The mean bursting pressure and data obtained from the biochemical assessment are displayed in Tables 1 and 2.

In the statistical assessment, bursting pressure was significantly higher on day 3 in the adrenomedullin-treated group (group 3) than in the nontreated group (group 1).
Additionally, when the hydroxyproline levels were compared, group 3 was significantly higher $(p=0.007)$. When the mean bursting pressures and hydroxyproline levels were compared between groups 2 and 4 on day 7 , the difference between bursting pressures were not significant; however, the adrenomedullin-treated group did show significantly higher hydroxyproline levels $(p=0.03)$.

With regard to the markers of the oxidative damage, MDA and NO levels were significantly lower in the adrenomedullin-treated group than in the nontreated groups on days 3 and 7 (MDA day $3 p=0.005$, MDA day 7 $p=0.003$, NO day $3 p=0.003$, and NO day $7 p=0.002$ ).

When VEGF levels were compared, no statistically significant difference was observed between the treated and control groups on either day 3 , or day 7 ( $p=0.6$ and $p=0.56$, respectively).

A graph comparing MDA levels for each pair of groups is displayed in Figure 1.

Histopathological differences between groups on day 3 (groups 1 and 3) and on day 7 (groups 2 and 4) are shown in Tables 3 and 4 .

The histopathological parameters, including inflammatory variations, mononuclear cell infiltration, epithelialization, capillary formation, necrosis, exudation, and fibroblastic activity displayed significant variations among all of the groups. Moderate or very strong infiltration of neutrophils was observed in all of the rats in groups 1 and 2, in three rats $(37.5 \%)$ in group 3 , and in three rats $(42 \%)$ in group 4 . Additionally, the infiltration of neutrophils was significantly higher in the untreated groups than in the adrenomedullintreated groups on both day 3 and 7. Moderate or strong capillary formation was observed in six $(75 \%)$ rats in group 1 , in seven (90\%) rats in group 2, in six (75\%) rats in group 3, and in five $(60 \%)$ rats in group 4 . When capillary formation was compared between groups, no statistically significant difference was observed on either day 3 , or day 7 . Moderate or high levels of necrosis were observed in all of the rats in groups 1 and 2. The levels of necrosis in groups 3 and 4 were significantly lower than in groups 1 and 2, respectively

Table 2 - Biochemical assessment and bursting pressures in groups 2 and 4, sacrificed on postoperative day 7.

\begin{tabular}{|c|c|c|c|c|c|}
\hline \multirow{2}{*}{ Parameters } & \multicolumn{2}{|c|}{ Group 2} & \multicolumn{3}{|c|}{ Group 4} \\
\hline & Mean & $S D$ & Mean & $S D$ & $p$-value \\
\hline IL-6 (pg/ml/mg tissue) & 3.31 & \pm 0.38 & 2.88 & \pm 0.16 & 0.013 \\
\hline$T N F-\alpha(\mathrm{ng} / \mathrm{ml} / \mathrm{mg}$ tissue $)$ & 3.52 & \pm 0.18 & 3.23 & \pm 0.23 & 0.048 \\
\hline MDA ( $\mu \mathrm{g} / \mathrm{ml} / \mathrm{mg}$ tissue) & 1.48 & \pm 0.21 & 1.09 & \pm 0.11 & 0.003 \\
\hline NO (pg/ml/mg tissue) & 2.01 & \pm 0.17 & 1.26 & \pm 0.25 & 0.002 \\
\hline VEGF (pg/ml/mg tissue) & 46.42 & \pm 7.54 & 48.42 & \pm 4.19 & 0.564 \\
\hline Hydroxyproline ( $\mu \mathrm{g} / \mathrm{tissue}$ & 345 & \pm 43.96 & 397.14 & \pm 29.24 & 0.013 \\
\hline Bursting pressure $(\mathrm{mmHg})$ & 148.28 & \pm 6.23 & 177.14 & \pm 5.89 & $<0.001$ \\
\hline
\end{tabular}




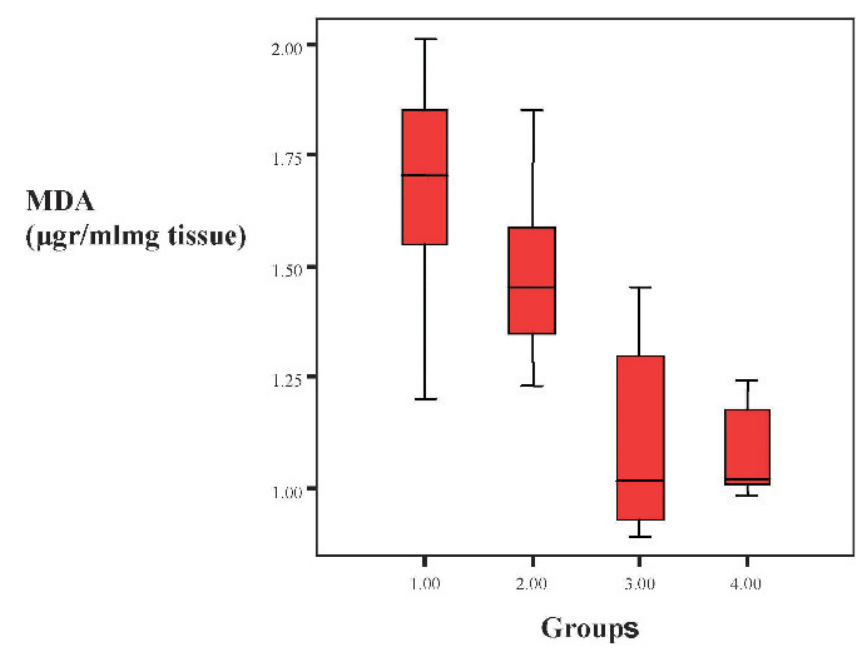

Figure 1 - MDA levels in groups 1 and 3 and in groups 2 and 4 are significantly different ( $p<0.05$ for each).

$(p<0.001$ for each). Moderate or very strong fibroblastic activity was observed in two (25\%) group 1 rats, in six $(80 \%)$ group 2 rats, in five (65\%) group 3 rats and in six (60\%) group 4 rats. Moderate or severe epithelialization was observed in all of the groups. However, a statistically significant difference was not observed between groups 1 and 3 or groups 2 and 4 in either epithelialization or fibroblastic activity.

\section{DISCUSSION}

Anastomotic leakage and anastomotic dehiscence increase mortality and morbidity and have serious consequences in colorectal surgery. Despite advancements in suture techniques and suture materials, anastomotic leakage occurs in 0 to $35 \%$ of colorectal surgeries. ${ }^{16}$ Although numerous local and systemic factors are responsible for this high incidence, intestinal blood flow, oxygenation, blood transfusion, surgical technique, suture materials, fecal contamination, peritoneal sepsis, anastomotic dehiscence, intestinal obstruction, and necrosis can all be considered directly related causes.

The healing of colonic anastomosis is a complex process correlated with inflammation, re-epithelialization and collagen metabolism. During the primary inflammatory response, including the first stage of anastomosis healing, collagen lysis begins with the release of cytokines and the migration of leukocytes. Local bacterial contamination in the environment results in re-epithelialization and a secondary inflammatory response at the wound boundaries. Collagen lysis continues during the secondary inflammatory phase as well. Anastomotic tensile strength is affected by the decrease in collagen lysis, new collagen synthesis and the number of bridges between collagen fibers. Primary inflammatory response, mucosal re-epithelialization, secondary inflammatory response and collagen maturation speed are the most important factors in anastomotic healing. Anastomotic tensile strength is based on collagen fibril settling within the submucosal layer. ${ }^{16}$

Agents that effectively promote the pathophysiological process of healing have been investigated in studies of colon anastomosis. These agents either induce wound healing or increase vascularization and decrease the septic state. Generally, local blood flow in the anastomotic site is the most important factor in anastomotic healing. The occurrence of anastomotic leakage in ischemic colonic anastomosis is about 35\%, which is higher than that of normal anastomosis. Thus, we chose to use ischemic colonic anastomosis as an experimental model in our study. Clinically, ischemic colonic anastomosis often occurs in operations performed under urgent conditions or in operations required for reasons other than intestinal problems, such as aortic surgery or during the resection of large tumors involving the intestinal mesentery when intestinal nutrition is affected. ${ }^{17}$ An agent that effectively increases anastomotic reliability during such conditions has not yet been found.

Numerous agents to treat anastomotic leakage have been examined. Aslan et al. ${ }^{18}$ used mesalamine (5-ASA) to improve healing at the site of colonic anastomosis due to its anti-inflammatory and oxygen free radical-scavenging effects. Çevikel et al. ${ }^{19}$ also examined the role of high-dose ascorbic acid supplementation and investigated the effects of ascorbic acid supplementation on collagen accumulation and the inflammatory response. They observed that ascorbic acid supplementation had a positive effect on the improvement of colonic anastomoses. In another study, Marc et al. ${ }^{20}$ found that doxycycline supported the matrix structure and increased matrix metalloproteinase and collagen accumulation at the anastomotic site.

The description of ADM by Kitamura et al. ${ }^{21}$ in 1993 attracted the attention of numerous investigators. In 2001 Hay and $S i^{22}$ conducted receptor typing of ADM. They were of the opinion that this receptor type behaved as a calcitonin-related peptide receptor. Its presence was observed in the duodenal, jejunal, stomach, cecal, and colon mucosae, as well as in smooth muscles. In this study, we assess the role of ADM in ischemic colonic anastomosis. To date, the effect of ADM on intestinal mucosae has remained unclear. Kitamura et al. ${ }^{21}$ reported that ADM is secreted from a subgroup of enterochromaffin cells in the gastrointestinal system. Mulder et al. reported the insulinotropic effects of ADM on the gastrointestinal system. Clemeti et

Table 3 - Histopathological differences between groups 1 and 3, sacrificed on postoperative day 3.

\begin{tabular}{|c|c|c|c|c|c|}
\hline \multirow[t]{2}{*}{ Parameters (scores) } & \multicolumn{2}{|c|}{ Group 1} & \multicolumn{3}{|c|}{ Group 3} \\
\hline & Mean & $S D$ & Mean & $S D$ & p-value \\
\hline Neutrophil infiltration & 2.65 & \pm 0.51 & 1.38 & \pm 0.51 & 0.001 \\
\hline Mononuclear infiltration & 1.88 & \pm 0.64 & 1.25 & \pm 0.46 & 0.054 \\
\hline Fibrobastic activity & 1.25 & \pm 0.46 & 1.88 & \pm 0.83 & 0.072 \\
\hline Epithelization & 0.63 & \pm 0.51 & 1.00 & \pm 0.75 & 0.068 \\
\hline Necrosis & 2.38 & \pm 0.51 & 0.88 & \pm 0.83 & 0.001 \\
\hline Capillary formation & 2 & \pm 0.75 & 2.13 & \pm 0.83 & 0.65 \\
\hline Exudation scoring & 2.75 & \pm 0.46 & 1.13 & \pm 0.35 & 0.001 \\
\hline Serositis scoring & 2.5 & \pm 0.53 & 1.38 & \pm 0.51 & 0.001 \\
\hline
\end{tabular}


Table 4 - Histopathological differences between groups 2 and 4, sacrificed on postoperative day 7.

\begin{tabular}{|c|c|c|c|c|c|}
\hline \multirow[t]{2}{*}{ Parameters (scores) } & \multicolumn{2}{|c|}{ Group 2} & \multicolumn{3}{|c|}{ Group 4} \\
\hline & Mean & $S D$ & Mean & $S D$ & $p$-value \\
\hline Neutrophil infiltration & 2.75 & \pm 0.46 & 1.88 & \pm 0.64 & 0.042 \\
\hline Mononuclear infiltration & 2.5 & \pm 0.75 & 1.38 & \pm 0.74 & 0.02 \\
\hline Fibrobastic activity & 1.75 & \pm 0.7 & 2.5 & \pm 0.53 & 0.06 \\
\hline Epithelialization & 0.75 & \pm 0.46 & 1.13 & \pm 0.35 & 0.065 \\
\hline Necrosis & 2.62 & \pm 0.51 & 1.13 & \pm 0.64 & 0.0025 \\
\hline Capillary formation & 2.13 & \pm 0.64 & 1.13 & \pm 0.64 & 0.001 \\
\hline Exudation scoring & 2.25 & \pm 0.7 & 0.75 & \pm 0.46 & 0.001 \\
\hline Serositis scoring & 0.75 & \pm 0.46 & 1.13 & \pm 0.64 & 0.001 \\
\hline
\end{tabular}

al. $^{23}$ determined that ADM hampered gastric mucosal damage and published its effects on the gastric artery in 2002. ADM is a strong stimulator of angiogenesis whose secretion is required for normal vascular development; however, its excessive release may also be either a cause or a consequence of tumor development. ${ }^{24} \mathrm{ADM}$ is secreted from microvascular endothelial cells during hypoxia and ischemia. ${ }^{25}$ The effects of ADM on DNA synthesis and cell proliferation, especially in rats, suggest that ADM has a strong antiproliferative effect via cAMP. ${ }^{26}$

The vasoactive effects of ADM are its most well established, as it is known to increase blood flow to brain, heart, and kidneys and to cause hypotension following intravenous administration. ${ }^{27}$

Additionally, we predicted that ADM could negatively affect colonic blood flow due to its hypotensive effects. However, less oxidative damage was observed with ADM administration, even though it induced more revascularization than was seen in the control groups. Moreover, hydroxyproline levels, determined spectrophotometrically, increased significantly in the ADM-treated groups. This demonstrates that ADM's endothelial protective effects and its ability to reduce oxidative damage without increasing neovascularization at ischemic sites are dominant over the hypotensive effect of ADM on the intestines. Additionally, necrosis and inflammation were less prevalent in the ADM-treated groups than in the control groups. These differences were consistent with the biochemical parameters observed in groups 3 and 4 .

The effects of ADM on DNA synthesis and cell proliferation, especially in rats, have shown that ADM has a strong antiproliferative effect via cAMP. ${ }^{27}$ However, whether the vasodilatory and growth-inhibiting effects of ADM in vascular cells are in contrast with the vasoconstrictor/ proliferative effects of endothelium and angiotensin II remain to be determined. ${ }^{28}$

A typical dose of ADM to aid ischemic colonic anastomosis healing has not been designated in the literature. We based our $\mathrm{ADM}$ dose on those reported to be effective on ischemic tissue in the literature, and this dose was given as a postoperative continuation dose. To date, this investigation is the only study performed in this field. Therefore, commenting on the results with respect to dose and administration design (single dose or continuous treatment) is rather difficult.

\section{ACKNOWLEDGMENTS}

We would like to thank Ahu Kemik MD, for biochemical analysis.

\section{REFERENCES}

1. Nasirkhan MU, Abir F, Longo W, Kozol R. Anastomotic disruption after large bowel resection. World J Gastroenterol. 2006;12:2497-504.
2. Thornton FJ, Barbul A. Healing in the gastrointestinal tract. Surg Clin North Am. 1997;77:549-73, doi: 10.1016/S0039-6109(05)70568-5.

3. Karatepe O, Cakir A, Unal O, Battal M, Adas G, Kamali G, Kemik A, Aydin T, Kamali S, Karahan SR, Aksoy M. Iloprost reduces colonic injury in ischemic colitis in rats. Acta Cir Bras. 2011;26:220-6, doi: 10.1590/ S0102-86502011000300011.

4. Garcia JG, Criado FJ, Persona MA, Alonso AG. Healing of colonic ischemic anastomoses in the rat: role of superoxide radicals. Dis Colon Rectum. 1998;41:892-5, doi: 10.1007/BF02235374.

5. Kandis H, Karapolat S, Yildirim U, Saritas A, Gezer S, Memisogullari R. Effects of Urtica dioica on hepatic ischemia-reperfusion injury in rats. Clinics. 2010;65:1357-61, doi: 10.1590/S1807-59322010001200021.

6. Marjanovic G, Jüttner E, zur Hausen A, Theodor Hopt U, Obermaier R. Ischemic preconditioning improves stability of intestinal anastomoses in rats. Int J Colorectal Dis. 2009;24:975-81, doi: 10.1007/s00384-0090696-0

7. Kohno M, Kano H, Horio T, Yokokawa K, Yasunari K, Takeda T. Inhibition of endothelin production by adrenomedullin in vascular smooth muscle cells. Hypertension. 1995;25:1185-90.

8. Horio T, Kohno M, Kano H, Ikeda M, Yasunari K, Yokokawa K, et al. Adrenomedullin as a novel antimigration factor of vascular smooth muscle cells. Circ Res. 1995;77:660-4.

9. Kato K, Yin H, Agata J, Yoshida H, Chao L, Chao J. Adrenomedullin gene delivery attenuates myocardial infarction and apoptosis after ischemia and reperfusion. Am J Physiol Heart Circ Physiol. 2003;285:1506-14.

10. Yin H, Chao L and Chao J. Adrenomedullin protects against myokardial apoptosis after ischemia/reperfusion through activation of Akt-GSK signaling. Hypertension. 2004;43:109-16.

11. Kita T, Kitamura K, Kuwasako K, Kawamoto M, Eto T. Short-term modulation of the renin-angiotensin system does not alter plasma adrenomedullin concentrations in humans. J Hypertens. 1998;16:2057-62, doi: 10.1097/00004872-199816121-00030.

12. Hinson JP, Kapas S, Smith DM. Adrenomedullin, a multifunctional regulatory peptide. Endocr Rev. 2000; 21:138-167, doi: 10.1210/er.21.2.138.

13. Isumi $Y$, Shoji H, Sugo S, Tochimoto T, Yoshioka M, Kangawa K, et al. Regulation of adrenomedullin production in rat endothelial cells. Endocrinology. 1998;139:838-46, doi: 10.1210/en.139.3.838.

14. Kapas S, Martinez A, Cuttitta F, Hinson JP. Local production and action of adrenomedullin in the rat adrenal glomerulosa. J Endocrinol. 1998;156:47784, doi: $10.1677 /$ joe. 0.1560477.

15. Kivirikko KI, Prockop DJ. Partial characterization of protocollagen from embryonic cartilage. Biochem J. 1967;102:432-42.

16. Schrock TR, Deveney CW, Dunphy JE. Factors contributing to leakage of colonic anastomoses. Ann Surg. 1973;177:513-8, doi: 10.1097/00000658197305000-00002.

17. Rosoky RM, Wolosker N, Nasser M, Zerati AE, Gidlund M, Puech-Leão P. Oxidized low-density lipoprotein and ankle-brachial pressure index in patients with clinically evident peripheral arterial disease. Clinics. 2010;65:383-7, doi: 10.1590/S1807-59322010000400006.

18. Ahmet Aslan, Muhyittin Temiza, Sibel Hakverdic, Gurbuz Polatb, Cemil Tumera, c, AbdulkerimTemiza, c. Elif Canbolanta: Effect of mesalamine on healing in experimental colon anastomosis: A randomised experimental study Journal of surgery 2008.

19. Carnieto A Jr, Dourado PM, Luz PL, Chagas AC. Selective cyclooxygenase-2 inhibition protects against myocardial damage in experimental acute ischemia. Clinics. 2009;64:245-52, doi: 10.1590/S1807-59322009000300016.

20. Siemonsma MA, de Hingh IH, de Man BM, Lomme RM, Verhofstad AA, Hendriks T. Let all: Doxycycline improves wound strength after intestinal anastomosis in the rat. Surgery. 2003;133:268-76, doi: 10.1067/ msy.2003.27.

21. Kitamura K, Sakata J, Kangawa K, Kojima M, Matsuo H, Eto T. Cloning and characterization of cDNAencoding a precursor for human adrenomedullin. Biocem Biophys Res Commun. 1993;194:720-5, doi: 10.1006/ bbrc.1993.1881.

22. Hay DL, Smith DM. Adrenomedullin receptors: molecular identity and function. Peptides. 2001;22:1753-63, doi: 10.1016/S0196-9781(01)00532-0. 
23. Clementi G, Caruso A, Cutuli VM, Managano NG, Salomone S, Lempereur $\mathrm{L}$, et al. Gastroprotective effect of adrenomedullin administered subcutaneously in the rat. Peptides. 2002;23:1149-53, doi: 10.1016/S01969781(02)00048-7.

24. Bunton DC, Petrie MC, Hillier C, Johnston F, McMurray JJ. The clinical relevance of adrenomedullin: a promising profile?. Pharmacol Ther. 2004;103:179-201, doi: 10.1016/j.pharmthera.2004.07.002.

25. Nikitenko LL, Smith DM, Bicknell R, Rees MC. Transcriptional regulation of the CRLR gene in human microvascular endothelial cells by hipoxia. FASEB J. 2003;17:1499-1501.
26. Jougasaki M, Burnett Jr JC. Adrenomedullin as a regulator peptide. Nephrol Dial Transplant. 2000;15:293-5, doi: 10.1093/ndt/15.3.293.

27. Sugo S, Minamino N, Shoji H, Kangawa K, Kitamura K, Eto T, et al. Production and secretion of adrenomedullin from vascular smooth muscle cell:augmented production by tumor necrosis factor-alpha. Biochem Biophys Res Commun. 1994;203:719-26, doi: 10.1006/bbrc. 1994.2241.

28. Ishimitsu T, Kojima M, Kangawa K, Hino J, Matsuoka H, Kitamura K, et al. Genomicstructure of human adrenomedullin gene. Biochem Biophys Res Commun. 1994;203:631-9, doi: 10.1006/bbrc.1994.2229. 